\title{
Um caleidoscópio de perspectivas sobre o Sistema Público de Escrituração Digital - SPED
}

A kaleidoscope of perspectives on Public Digital Bookkeeping System

Un caleidoscopio de perspectivas sobre el Sistema Público de Escrituración Digital

\section{Ricardo Vinícius Dias Jordão}

$\mathrm{PhD}$ in Management, Accounting and Finance pelo Center for Advanced Studies in Management and Economics (UE) em associação com o Swiss Management Center, Suíça. Professor do Mestrado em Administração da Fundação Pedro Leopoldo

Endereço: Av. Lincoln Diogo Viana, n॰ 830 - Dr. Lund

CEP: 33.600-000 - Pedro Leopoldo/MG - Brasil

E-mail: jordaoconsultor@yahoo.com.br

Telefone: +55 (31) 99858-2554

\section{Milton Santos Silva}

Mestre em Administração pela Fundação Pedro Leopoldo

Professor de graduação na Fundação Pedro Leopoldo

Endereço: Av. Lincoln Diogo Viana, n॰ 830 - Dr. Lund

CEP: 33.600-000 - Pedro Leopoldo/MG - Brasil

E-mail: miltinho.contabeis@gmail.com

Telefone: +55 (31) 996116283

\section{Maria Celeste Reis Lobos de Vasconcelos}

Doutora em Ciência da Informação pela Universidade Federal de Minas Gerais

Professora do Mestrado em Administração da Fundação Pedro Leopoldo

Endereço: Av. Lincoln Diogo Viana, no 830 - Dr. Lund

CEP: 33.600-000 - Pedro Leopoldo/MG - Brasil

E-mail: celeste.vasconcelos@fpl.edu.br

Telefone: +55 (31) 99982-7235

\section{Haroldo Guimarães Brasil}

Doutor em Economia pela Universidade Federal do Rio de Janeiro

Professor do Ibmec-MG

Endereço: R. Rio Grande do Norte, n॰ 300 - Funcionários

CEP: $30.130-130$ - Belo Horizonte /MG - Brasil

E-mail: haroldo.brasil@gmail.com

Telefone: +55 (31) 99791-9436

Artigo recebido em 02/10/2014. Revisado por pares em 15/07/2015. Reformulado em 11/10/2015. Recomendado para publicação em 21/10/2015 por Sandra Rolim Ensslin (Editora Científica). Publicado em 25/02/2016. 


\title{
Resumo
}

A pesquisa teve como objetivo analisar a percepção de empresários, contadores e órgãos fiscalizadores de Minas Gerais sobre a adoção do Sistema Público de Escrituração Digital (SPED). A pesquisa quantitativa e qualitativa do tipo survey baseou-se em um questionário semiestruturado com questôes abertas e fechadas, aplicadas a 130 respondentes. Os resultados evidenciam que o SPED promoveu avanços informacionais e tecnológicos, mais transparência e mudanças culturais; modernizou a sistemática de fiscalização e arrecadação; provocou inovação em sistemas e processos contábeis, empresariais e governamentais; e exigiu o aprendizado de novas metodologias, processos e tecnologias. Isso aumentou a eficiência tributária do governo e trouxe significativos impactos organizacionais, exigindo que as empresas inovassem em seus processos corporativos e de negócios. No geral, os resultados mostraram que os dirigentes de empresas, contadores e órgãos fiscalizadores precisam se preparar melhor para o uso do SPED e suas inovações, aperfeiçoando e investindo em atividades de gestão tributária.

Palavras-chave: Sistema Público de Escrituração Digital. Escrituração Contábil e Fiscal. Gestão Tributária.

\begin{abstract}
The research aimed to analyze the perception of businessmen, accountants and supervisory bodies of Minas Gerais - Brazil, on the adoption of the Public Digital Bookkeeping System. The quantitative and qualitative survey research was based on a semi-structured questionnaire with open and closed questions, applied to 130 respondents. The results show that the SPED promoted informational and technological advances, greater transparency and cultural changes; modernized the system of supervision and collection; led to innovation in accounting, business and government systems and processes; and required the learning of new methodologies, processes and technologies. This has increased the fiscal efficiency of the government and brought significant organizational impacts, demanding companies to innovate their corporate processes and business. Overall, the results showed that the leaders of businesses, accountants and regulatory agencies need to better prepare for the use of SPED and innovations, improving and investing in tax management activities.
\end{abstract}

Keywords: Public Digital Bookkeeping System. Bookkeeping Accounting and Tax. Tax Management.

\section{Resumen}

La investigación tuvo como objetivo analizar la percepción de empresarios, contadores y órganos fiscalizadores de Minas Gerais sobre la adopción del Sistema Público de Escrituración Digital (SPED). La investigación cuantitativa y cualitativa del tipo survey se basó en un cuestionario semiestructurado con cuestiones abiertas y cerradas, aplicadas a 130 encuestados. Los resultados muestran que el SPED promovió avances informativos y tecnológicos, más transparencia y cambios culturales; modernizó la sistemática de fiscalización y recaudación; provocó innovación en sistemas y procesos contables, empresariales y gubernamentales; y exigió el aprendizaje de nuevas metodologías, procesos y tecnologías. Eso aumentó la eficiencia tributaria del gobierno y trajo significativos impactos organizativos, exigiendo que las empresas innovasen en sus procesos corporativos y de negocios. En general, los resultados mostraron que los dirigentes de empresas, contadores y órganos fiscalizadores precisan prepararse mejor para el uso del SPED y sus innovaciones, perfeccionando e invirtiendo en actividades de gestión tributaria.

Palabras clave: Sistema Público de Escrituración Digital. Escrituración Contable y Fiscal. Gestión Tributaria.

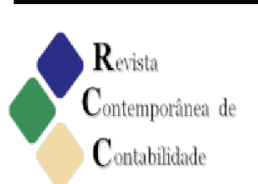

ISSN 2175-8069, UFSC, Florianópolis, v. 12, n. 26, p. 119-140, mai./ago. 2015 


\section{Introdução}

Com o advento da globalização e a evolução das Tecnologias de Informação e Comunicação (TIC), os governos de alguns países têm buscado criar maneiras de 'Governo Eletrônico' (GE) como forma de controle estratégico dos tributos (OKOT-UMA, 2001; CHEN et al., 2006). No Brasil, esse processo foi instituído, em 2007, com o advento do Sistema Público de Escrituração Digital (SPED) que, desde então, vem impactando organizações e sociedade. Entretanto, após decorridos vários anos do início dessa implantação, pouco se conhece da percepção dos vários atores envolvidos quanto aos aspectos facilitadores e dificultadores propiciados pelo Sistema, sendo esta uma significativa lacuna de pesquisa. Diante desse contexto, o problema de pesquisa pode ser sumarizado no seguinte questionamento: Quais as percepções de empresários, contadores e órgãos fiscalizadores sobre a adoção do SPED?

Assim, o objetivo da pesquisa, descrito neste artigo, consiste em analisar a percepção de empresários, contadores e órgãos fiscalizadores sobre a adoção do SPED. A justificativa de uma pesquisa se dá à medida que seus resultados contribuem para um segmento substancial da sociedade, como defendido por Jordão e Souza (2013) e Jordão et al. (2014). Mais do que a importância do tema ressaltada por Lizote e Mariot (2012), que asseveram sobre a magnitude e complexidade das mudanças organizacionais trazidas pelo SPED, o estudo em tela se justifica pela necessidade de entendimento dos impactos causados por ele na sistemática de tributação das empresas brasileiras, pois esse tema ainda é incipiente na literatura, especialmente na brasileira, na qual ainda há poucas análises sobre o assunto como destacam Geron et al. (2011). Adicionalmente, como lembram Futema et al. (2009), os efeitos das mudanças tributárias sobre as empresas são de grande interesse para as teorias de finanças e de gestão empresarial, além de serem uma questão de significativa relevância para a academia e a sociedade, justificando igualmente a realização da pesquisa e acentuando sua contribuição.

O artigo está apresentado em mais cinco seções para além desta Introdução. A seção dois traz a plataforma de sustentação teórica da pesquisa, sendo seguida pela seção três que traz os procedimentos metodológicos. A seção quatro apresenta os resultados da análise quantitativa; e a seção cinco, os resultados da análise qualitativa. A seção seis encerra o artigo, trazendo as principais conclusões em linha com os objetivos iniciais, seguida pelas referências bibliográficas utilizadas.

\section{Contabilidade \& Gestão Tributária: Uma análise do Sistema Público de Escrituração Digital}

A literatura internacional demonstra que os sistemas tributários da grande maioria dos países da América Latina possuem algumas similaridades como a composição de suas estruturas tributárias, restrições técnicas, econômicas, políticas e administrativas, além de um elevado indicador de sonegação (SABAINI; JIMÉNEZ, 2011). Esses países possuem estimativas de informalidade de quase três vezes o observado em países da Organização para a Cooperação e Desenvolvimento Econômico (OCDE), pertencendo à região que mais sonega no mundo (AHMED; RIDER, 2008). Não obstante, o Brasil tem uma das legislações fiscais mais complexas do mundo e de mais difícil aplicação (SIQUEIRA, 2005). As empresas, além de uma grande variedade de atividades tributárias, têm cerca de 170 obrigações acessórias para serem cumpridas, provocando deficiências na arrecadação (BRITTO, 2008). A preocupação das empresas, no que concerne ao cumprimento das obrigações perante os Fiscos federal, estadual e municipal, tem crescido expressivamente nos últimos anos (LIZOTE; MARIOT, 2012), levando algumas empresas a buscarem alternativas que permitam a redução do pagamento de tributos, o que, algumas vezes, pode ocorrer ilegalmente.

121 ISSN 2175-8069, UFSC, Florianópolis, v. 12, n. 26, p. 119-140, mai./ago. 2015 Revista 
A literatura internacional e a teoria de tributos também mostram que a evasão fiscal é um fenômeno universal, podendo ser afetada pelas estruturas econômicas e fiscais, atitudes sociais (TANZI; SHOME, 1993), além de outros elementos não econômicos como fonte, nível e tipos de renda (TANZI; SHOME, 1993; RICHARDSON, 2006), complexidade do sistema tributário, nível educacional (escolaridade), sentimento de justiça, moralidade fiscal (RICHARDSON, 2006), ou mesmo pela religiosidade das pessoas (TORGLER, 2006). Em geral, a literatura internacional aponta que, quando a carga tributária é muito alta e a probabilidade de detectar a sonegação é baixa, há maior propensão à sonegação (ALLINGHAM; SANDMO, 1972; ENGEL; HINES Jr, 2000). A ideia central defendida por Abdenur (2011) é que sonegação fiscal pode ser considerada como um dos fatores que mais comprometem o desenvolvimento de uma economia, especialmente quando se trata de países emergentes, como é o caso do Brasil.

Segundo um estudo recente do Instituto Brasileiro de Planejamento e Tributação (IBPT), os brasileiros trabalharam até 31 de maio de 2014 para pagar tributos, considerando que $41,37 \%$ do rendimento bruto dos contribuintes foram destinados ao recolhimento dos tributos federais, estaduais e municipais (IBPT, 2014). Uma pesquisa realizada pela organização britânica Tax Justice Network $(T J N)$ aponta que o Brasil é o primeiro país no mundo, em termos relativos, que mais perde dinheiro com a sonegação de impostos em todo o mundo, correspondendo a $11,24 \%$ em relação ao Produto Interno Bruto (PIB). Isso significa que deixa de arrecadar 280 bilhões de dólares com o não pagamento de tributos por ano. $\mathrm{O}$ mesmo estudo aponta que os Estados Unidos são o país que possui o maior valor absoluto de sonegação, perdendo 337 bilhões de dólares anualmente, mas isso representa apenas 2,23\% do PIB dessa nação, encontrando-se em quarto lugar entre os países do mundo que mais perdem dinheiro com a sonegação fiscal, em relação aos respectivos PIBs (TJN, 2011). Outro estudo, realizado por essa mesma organização, levantou que $4,9 \%$ do PIB mundial são perdidos devido à sonegação de impostos $(T J N, 2014)$.

Segundo Amaral et al. (2009), os contribuintes brasileiros muitas vezes agem por meio de atos ilícitos para fugir do alto custo tributário. Por outro lado, Maia (2012) lembra que o combate à sonegação não tem sido eficiente, visto que a fiscalização tributária no Brasil, até o ano de 2006, era feita de forma precária, pois a base da fiscalização dos órgãos fiscalizadores era menos fundamentada nas TICs do que nos dias de hoje, exigindo mais esforço para se encontrarem irregularidades com o modelo anterior de fiscalização.

Reconhecendo essa precariedade, alguns países buscaram meios de estabelecer um GE, cuja proposta consiste na integração das empresas e órgãos fiscalizadores por meio eletrônico. Esse termo foi utilizado pela primeira vez em 1999 nos Estados Unidos (CHEN et al., 2006). Segundo Duarte (2008), o SPED é uma forma de GE que passa a ser uma vigilância das empresas, em tempo real, pelos órgãos fiscalizadores, podendo ser comparado a um Big Brother fiscal, no qual os alvos são a obtenção de informações das operações realizadas pela empresa e o combate à sonegação. Nesse sentido, o SPED inovou a sistemática de fiscalização do governo com a proposta de reduzir a sonegação de tributos e, com isso, tornar mais equilibrada a concorrência entre as empresas que os recolhem e aquelas que não o fazem. Com a nova redação dada pelo Decreto $\mathrm{n}^{\circ} 7.979$, de 8 de abril de 2013, o SPED pode ser definido como o "instrumento que unifica as atividades de recepção, validação, armazenamento e autenticação de livros e documentos que integram a escrituração contábil e fiscal dos empresários e das pessoas jurídicas, inclusive imunes ou isentas,

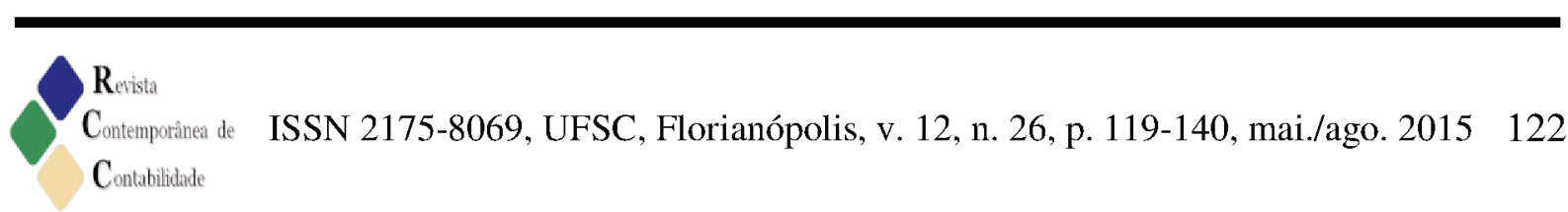


mediante fluxo único, computadorizado, de informações". O SPED consiste no cumprimento, de forma mais moderna, das obrigações acessórias para órgãos fiscalizadores por meio de arquivos eletrônicos digitais. As empresas deixam de enviar essas obrigações em papel e passam a enviá-las por meio digital on-line, assinadas digitalmente, utilizando um certificado do SPED. O SPED tem como objetivos promover a integração dos órgãos fiscalizadores mediante a padronização e o compartilhamento de informações contábeis e fiscais; racionalizar e uniformizar as obrigações acessórias para as empresas, com a transmissão única de distintas obrigações acessórias para diferentes órgãos fiscalizadores. Objetiva também diminuir a sonegação fiscal. Por isso, Lizote e Mariot (2012) observam que o governo vem desenvolvendo e inovando a cada ano seus controles e métodos de fiscalização, tendo apresentado significativa guinada com o desenvolvimento do SPED e de seus subprojetos.

Esse sistema veio com uma promessa de propiciar benefícios para os contribuintes, na visão de Dinis (2009), como a simplificação de obrigações acessórias, eliminação de digitação de notas fiscais, redução de erros de escrituração e de custos com impressão, aquisição de papel e formulários, além de melhor armazenamento de documentos, contribuindo para o impacto ambiental favorável.

Geron et al. (2011) analisaram se houve, nas empresas, melhorias operacionais quando da adoção do SPED. Na prática, os resultados empíricos obtidos por esses autores demonstraram que os contribuintes brasileiros não obtiveram resultados satisfatórios em termos de redução no tempo de emissão de uma nota fiscal, mais agilidade e produtividade no recebimento de mercadorias e nem reduções nas compras de papel. Muitos deles ainda tinham a perspectivas de que teriam benefícios no futuro, principalmente em relação à diminuição dos riscos de fraudes e a diminuição dos custos operacionais. Assim, do que fora dito, resta confrontar as percepções das diferentes partes interessadas para saber se, de fato e até que ponto, isso se justifica pelo prisma contábil e empresarial, ou se esse é apenas um mecanismo útil para o governo aumentar o controle e a fiscalização das empresas.

\section{Procedimentos Metodológicos}

A pesquisa consiste em um estudo explanatório e descritivo de natureza quantitativa e qualitativa (COOPER; SCHINDLER, 2003; GEORGE; BENNETT, 2005). Além da pesquisa bibliográfica, foi desenvolvida uma pesquisa de levantamento do tipo survey (COMIN et al., 2014) com base em variáveis extraídas da literatura, visando refletir a percepção de dirigentes de empresas, contadores e órgãos fiscalizadores, no período de 2007 a 2012, sobre o SPED. Geron et al. (2011) sugerem que esse método é suficientemente sensível para captar as especificidades inerentes à percepção dos efeitos causados pelo SPED nas empresas.

O universo de pesquisa selecionado se constituiu de empresários (32 diretores), contadores (51 profissionais) e órgãos fiscalizadores (47 auditores-fiscais). Embora não seja possível dimensionar a representatividade da amostra dos profissionais em relação à população total, tomou-se o cuidado de atentar para o mínimo estabelecido na literatura (HAIR et al., 2010; HAIR et al., 2011) de 30 observações. O método de amostragem, utilizado na pesquisa, foi do tipo intencional, cujos respondentes foram selecionados entre pessoas com as quais os pesquisadores tinham contato para facilitar o acesso às informações, sendo a seleção deles justificada pela tipicidade, ou seja, pela capacidade informativa que os 
respondentes detêm sobre o problema em tela (JORDÃO et al. 2015; JORDÃO, 2015). Além da pesquisa bibliográfica, foi desenvolvida uma pesquisa de levantamento do tipo survey para avaliar as percepções dos respondentes. Os informantes foram contatados no período de outubro de 2012 a janeiro de 2013, por e-mail e pessoalmente, por meio de visitas nos escritórios, repartições ou instalações comerciais ou industriais. Os contadores pesquisados ocupam cargos em empresas privadas ou são proprietários de escritórios de contabilidade que possuem experiência com o SPED em suas atividades profissionais. Os órgãos fiscalizadores são representados por auditores-fiscais do estado de Minas Gerais ou da Receita Federal, que têm vivenciado experiências com o projeto SPED desde 2006, quando se deu início à utilização da NF-eletrônica. Já os empresários são de empresas que estão utilizando o SPED rotineiramente desde o início da sua implantação. Os três grupos de respondentes atuam na região metropolitana de Belo Horizonte. Ressalta-se que a abordagem não probabilística para análise de dados amostrais impõe restrições quanto à generalização dos resultados obtidos. Contudo, conforme Granlund (2003), esse tipo de seleção se justifica, pois o acesso às informações consiste em uma das maiores dificuldades nesse tipo de pesquisa.

O instrumento de coleta de dados foi concebido com base em variáveis extraídas da literatura e submetido a um pré-teste com 10 pessoas, com o objetivo de verificar falhas, refiná-lo e aumentar sua confiabilidade. Depois da coleta dos dados, os resultados advindos das informações dos 130 respondentes foram submetidos às análises qualitativa e quantitativa. A parte quantitativa foi fundamentada em estatísticas descritivas e compilação por grupos por meio da avaliação de ranking médio. Os resultados dos testes estatísticos foram avaliados utilizando-se o programa Statistical Package for the Social Sciences (SPSS) e SmartPLS, gerando um conjunto de análises descritivas. Para avaliar a percepção dos contadores e fiscais, adotou-se uma escala do tipo Likert de cinco categorias de respostas (COMIN et al., 2014), que vão de "discordo totalmente" a "concordo totalmente". No final do questionário de pesquisa, foram disponibilizadas quatro questões abertas, visando à análise qualitativa. Para verificar se existe relação entre os itens avaliados e o perfil do respondente utilizou-se uma técnica intitulada Chi-Square Automatic Interaction Detector (CHAID), proposta por Kass, em 1980, que permite avaliar o relacionamento entre uma variável dependente e outras em nível categórico ou contínuo, avaliadas pelo valor ' $p$ ' obtido. O resultado é apresentado em forma de árvore, na qual são dispostas as variáveis preditoras que mais estejam associadas à variável dependente.

De forma a aumentar a validade interna do estudo, procurou-se agregar informações coletadas em outras fontes de evidência. Esse processo é conhecido como triangulação (JICK, 1979). Na triangulação, realizou-se uma análise intergrupos e intragrupos, visando construir uma cadeia de evidências e dar mais robustez ao estudo, seguindo as recomendações de Eisenhardt (1989). Assim, sempre que possível, as informações advindas de uma fonte foram confrontadas com as de outras para confirmá-las e validá-las ou então refutá-las. Salienta-se que, no presente trabalho, esse procedimento iniciou com as próprias estatísticas descritivas agregadas e, depois, buscou-se analisar os diferentes tópicos em cada um dos três grupos de respondentes separadamente. Depois, procurou-se realizar uma análise qualitativa por meio da técnica de análise de conteúdo, tentando compreender o significado simbólico das informações contidas nas questões abertas, conforme preconizado por Bardin (2004). Por motivo de parcimônia, os resultados são apresentados ao longo do texto em tabelas e discutidos de forma já triangulada, ou seja, sem segregação explícita dos resultados por fonte 
de dados (JORDÃO; NOVAS, 2013). Não obstante, a validade externa foi ampliada pelo confronto com o referencial de base, corroborando, complementando ou contradizendo os resultados anteriores e os fundamentos contidos na plataforma de sustentação teórica.

\section{Apresentação e Análise dos Resultados da Pesquisa Quantitativa}

Nesta seção, apresentam-se os resultados da pesquisa quantitativa, iniciando por uma comparação da visão geral dos respondentes. Na sequência, é feita uma análise das percepções dos efeitos provocados pelo SPED e as perspectivas futuras sobre ele em cada grupo de respondentes (iniciando com os empresários, depois contadores e órgãos fiscalizadores), com base em análises quantitativas e qualitativas, respectivamente. A análise do resultado da tipologia dos respondentes mostrou algum um equilíbrio entre essas três categorias, mas com preponderância de contadores, pois havia $36 \%$ de fiscais, $25 \%$ de empresas e $39 \%$ de contadores. As premissas que deram suporte à parte quantitativa da pesquisa foram desmembradas em 12 questões, tendo sido avaliadas pelo valor $p$, sendo que, valores $p$ superiores a 0,05 indicaram ausência de diferença significativa de percepção entre contadores, órgãos fiscalizadores e empresários. Os resultados estatísticos da amostra com a apresentação de diferenças entre os grupos constam da Tabela 1.

Tabela 1 -Similaridade de percepção dos respondentes sobre o SPED

\begin{tabular}{|c|c|c|c|c|c|}
\hline $\mathbf{N}^{\mathbf{o}}$ & QUESTÕES & Média & $\begin{array}{l}\text { Desvio } \\
\text { Padrão }\end{array}$ & $\begin{array}{l}\text { CHAID } \\
\text { (Valor p) }\end{array}$ & $\begin{array}{l}\text { Diferenças de } \\
\text { percepção }\end{array}$ \\
\hline 1 & $\begin{array}{l}\text { Com a utilização do SPED, os órgãos fiscalizadores } \\
\text { ficaram mais eficientes para identificar e combater } \\
\text { fraudes tributárias. }\end{array}$ & 4,25 & 0,79 & 0,23 & Não \\
\hline 2 & As empresas encontram-se preparadas para o SPED. & 2,61 & 0,91 & 0,00 & Sim \\
\hline 3 & $\begin{array}{l}\text { A profissão de contador passou a ser valorizada com o } \\
\text { advento do SPED. }\end{array}$ & 3,58 & 0,96 & 0,10 & Não \\
\hline 4 & $\begin{array}{l}\text { Com o SPED, aumentou o compartilhamento de } \\
\text { informações entre os órgãos fiscalizadores e as } \\
\text { empresas. }\end{array}$ & 4,27 & 0,74 & 0,00 & Sim \\
\hline 5 & O SPED contribuiu para redução da sonegação. & 3,82 & 0,93 & 0,00 & Sim \\
\hline 6 & $\begin{array}{l}\text { A arrecadação de tributos aumentou em função do } \\
\text { SPED. }\end{array}$ & 3,47 & 0,93 & 0,03 & Sim \\
\hline 7 & $\begin{array}{l}\text { As empresas estão sendo mais fiscalizadas após a } \\
\text { implementação do SPED. }\end{array}$ & 3,48 & 0,88 & 0,05 & $\operatorname{Sim}$ \\
\hline 8 & $\begin{array}{l}\text { Houve redução de custos operacionais para sua entidade, } \\
\text { em função da adoção do SPED. }\end{array}$ & 2,54 & 1,06 & 0,00 & Sim \\
\hline 9 & $\begin{array}{l}\text { A adoção do SPED provocou investimentos adicionais } \\
\text { na sua entidade. }\end{array}$ & 4,02 & 0,98 & 0,00 & Sim \\
\hline 10 & $\begin{array}{l}\text { O SPED tem sido um meio seguro de transmissão das } \\
\text { informações para os órgãos fiscalizadores. }\end{array}$ & 4,08 & 0,85 & 0,87 & Não \\
\hline 11 & $\begin{array}{l}\text { O SPED provocou melhorias no cumprimento das } \\
\text { obrigações tributárias acessórias. }\end{array}$ & 3,75 & 0,88 & 0,18 & Não \\
\hline 12 & $\begin{array}{l}\text { O SPED provocou mudanças culturais na sua entidade } \\
\text { (como, por exemplo, a impressão de livros e documentos } \\
\text { em papel). }\end{array}$ & 3,88 & 0,90 & 0,00 & Sim \\
\hline
\end{tabular}

Fonte: Dados da pesquisa.

125 ISSN 2175-8069, UFSC, Florianópolis, v. 12, n. 26, p. 119-140, mai./ago. 2015 
A análise dos dados mostrou uma similaridade de percepção entre empresários, contadores e órgãos fiscalizadores nas questões $1,3,10$ e 11, indicando que, na percepção dos respondentes, (i) o SPED contribuiu para que os órgãos fiscalizadores ficassem mais eficientes para identificar e combater fraudes tributárias; (ii) a profissão de contador passou a ser valorizada; (iii) o SPED tem sido um meio seguro de transmissão de informações para os órgãos fiscalizadores; e (iv) o SPED provocou melhorias no cumprimento das obrigações tributárias acessórias. Adicionalmente, foi possível observar, pelo valor obtido abaixo da média, que os respondentes discordam que (v) as empresas se encontram preparadas para o SPED; e (vi) tenha havido redução de custos operacionais em função da adoção do SPED. Um detalhamento das percepções por grupo de respondentes por ser observado na seção 4.1

\subsection{Descrição e análise quantitativa dos resultados dos respondentes}

Estão apresentados na Tabela 2 os resultados obtidos com base na verificação das questões respondidas pelos dirigentes de empresas com o intuito de promover um entendimento mais detalhado da sua percepção e realizar um cotejamento dela com a percepção dos contadores e órgãos fiscalizadores. A análise da primeira questão revela que os órgãos fiscalizadores ficaram mais eficientes para identificar e combater fraudes tributárias depois do advento do SPED. Bezerra (2011) já evidenciara isso ao afirmar que o Fisco está se tornando mais rápido na identificação de fraudes tributárias, obrigando as empresas a se adaptarem a essa nova realidade.

Os dados constantes da Tabela 2 evidenciam que tanto os dirigentes de empresas, quanto os contadores foram contrários às assertivas contidas na segunda e na oitava questões, entendendo (com alguma heterogeneidade de percepções pela variação em torno da média nessas questões) que as empresas não se encontram preparadas para o SPED e nem houve redução de custos em função da sua adoção. Esse também é o pensamento de Maia (2012), que afirma que as empresas ainda precisam se adaptar a essa era da tributação digital do SPED e o desconhecimento e despreparo podem acarretar prejuízos. Essa percepção foi bastante divergente do grupo dos órgãos fiscalizadores, cujo entendimento foi de indiferença sobre tais quesitos. $\mathrm{O}$ entendimento dos três grupos, portanto, contraria as ideias de Gegers (2012).

Da análise da questão 3, identificou-se que os contadores percebem que sua profissão passou a ser mais valorizada com o advento do SPED, assim como os empresários, corroborando as observações de Silva e Krüger (2013). Já os auditores-fiscais tiveram um entendimento de indiferença sobre o quesito. Nenhum dos três grupos teve uma percepção harmônica entre os respondentes, havendo divergências de opinião em todos eles.

A análise da questão 4 revela que o SPED aumentou o compartilhamento de informações entre os órgãos fiscalizadores e as empresas na opinião de todos os três grupos de respondentes, havendo percepções similares entre os respondentes sobre esse quesito, concordando com Salvino et al. (2011) e Silva e Krüger (2013).

A análise da questão 4 revela que o SPED aumentou o compartilhamento de informações entre os órgãos fiscalizadores e as empresas na opinião de todos os três grupos de respondentes, havendo percepções similares entre os respondentes sobre esse quesito, concordando com Salvino et al. (2011) e Silva e Krüger (2013). 
Tabela 2 -Estatísticas Descritivas sobre a Percepção dos Respondentes

\begin{tabular}{|c|c|c|c|c|c|c|c|c|c|c|c|c|}
\hline AFIRMAÇÕES & 1 & 2 & 3 & 4 & 5 & 6 & 7 & 8 & 9 & 10 & 11 & 12 \\
\hline \multicolumn{13}{|c|}{ Percepção de dirigentes de empresas sobre o SPED } \\
\hline \multirow{2}{*}{$\begin{array}{l}\text { Média } \\
\text { Desvio Padrão }\end{array}$} & 4,47 & 2,25 & 3,88 & 4,59 & 4,06 & 3,72 & 3,66 & 2,16 & 4,66 & 4,16 & 3,97 & 4,28 \\
\hline & 0,57 & 0,84 & 0,98 & 0,56 & 0,84 & 0,99 & 0,87 & 1,27 & 0,48 & 0,77 & 0,78 & 0,73 \\
\hline \multirow{2}{*}{$\begin{array}{l}\text { Moda } \\
\text { Mediana }\end{array}$} & 5 & 2 & 4 & 5 & 4 & 4 & 4 & 2 & 5 & 4 & 4 & 4 \\
\hline & 5 & 2 & 4 & 5 & 4 & 4 & 4 & 2 & 5 & 4 & 4 & 4 \\
\hline \multicolumn{13}{|c|}{ Percepção de contadores sobre o SPED } \\
\hline \multirow{4}{*}{$\begin{array}{l}\text { Média } \\
\text { Desvio Padrão } \\
\text { Moda } \\
\text { Mediana }\end{array}$} & 4,24 & 2,27 & 3,61 & 4,33 & 4,12 & 3,61 & 3,63 & 2,2 & 4,02 & 4,16 & 3,67 & 3,78 \\
\hline & 0,86 & 0,67 & 0,98 & 0,77 & 0,79 & 0,92 & 0,92 & 0,85 & 0,91 & 0,68 & 0,95 & 1,06 \\
\hline & 4 & 2 & 4 & 5 & 4 & 4 & 4 & 2 & 4 & 4 & 4 & 4 \\
\hline & 4 & 2 & 4 & 4 & 4 & 4 & 4 & 2 & 4 & 4 & 4 & 4 \\
\hline \multicolumn{13}{|c|}{ Percepção de órgãos fiscalizadores sobre o SPED } \\
\hline \multirow{4}{*}{$\begin{array}{l}\text { Média } \\
\text { Desvio Padrão } \\
\text { Moda } \\
\text { Mediana }\end{array}$} & 4,15 & 3,21 & 3,34 & 4 & 3,32 & 3,21 & 3,26 & 3,13 & 3,64 & 4 & 3,7 & 3,68 \\
\hline & 0,72 & 0,88 & 0,87 & 0,75 & 0,91 & 0,81 & 0,79 & 0,82 & 1,03 & 0,98 & 0,83 & 0,78 \\
\hline & 4 & 3 & 3 & 4 & 3 & 3 & 3 & 3 & 4 & 4 & 3 & 4 \\
\hline & 4 & 3 & 3 & 4 & 3 & 3 & 3 & 3 & 4 & 4 & 4 & 4 \\
\hline
\end{tabular}

Fonte: Dados da pesquisa.

A questão 6 evidencia, com menor grau de concordância do que a afirmativa anterior, que a arrecadação de tributos aumentou em função do SPED na visão de empresas e contadores, embora haja alguns respondentes desses dois grupos inseguros sobre o quesito e vários outros entre os auditores-fiscais que tiveram também um entendimento de indiferença, alinhando-se, em parte, ao pensamento de Ilarino (2010).

Com a análise da questão 7 , é possível perceber que as empresas têm sido mais fiscalizadas na percepção dos contadores e empresários com o advento do SPED. Pode-se perceber também que o desvio padrão elevado indica que vários desses respondentes não acreditam nisso. Ainda assim, a tendência apontada pela mediana evidencia a confirmação do item avaliado, ao contrário dos auditores-fiscais que, novamente, se mostraram indiferentes ao quesito, confirmando, parcialmente, Ribeiro (2012).

A análise da questão 9 mostra que a adoção do SPED provocou investimentos adicionais em todas as entidades investigadas, sendo esse ponto observado de forma mais expressiva nas empresas, depois nos escritórios contábeis e depois nos órgãos fiscalizadores. Os dados indicam que a percepção de alguns respondentes foi indiferente nesse aspecto, mas, em geral, confirmaram os resultados de Muraro et al. (2014) que constataram uma necessidade de investimentos adicionais em função da adoção da sistemática trazida pelo novo modelo de escrituração contábil e fiscal.

Os resultados da questão 10 apontam que, na opinião de todos os respondentes, a nova forma de transmissão das informações das empresas para os órgãos fiscalizadores é mais segura do que a anterior, corroborando os achados de Salvino et al. (2011), que ressaltam que o SPED é um meio seguro para a transmissão de obrigações acessórias e para a emissão de Notas Fiscais Eletrônicas (NF-e) que são validadas pelas Secretarias de Fazenda estaduais e

127 ISSN 2175-8069, UFSC, Florianópolis, v. 12, n. 26, p. 119-140, mai./ago. 2015 
federais. A análise comparativa da questão 10 revelou um nível de confirmação similar entre os três grupos de respondentes, sendo um pouco mais uniforme e expressivo entre os contadores e dirigentes do que entre os auditores-fiscais.

Com a análise da questão 11 , foi possível constatar que o SPED provocou melhorias no cumprimento das obrigações acessórias na visão dos três grupos de respondentes, havendo mais concordância e uniformidade de entendimento entre os empresários e menos entre os contadores, confirmando os achados de Muraro et al. (2014).

Finalmente, a questão 12 avaliou se o SPED provocou mudanças culturais. A análise dos dados confirmou essa premissa em todas as entidades analisadas, sendo possível verificar que o SPED provocou mudanças culturais, observando-se que as empresas passaram por mudanças na cultura do papel com a troca de impressão de livros e documentos fiscais por arquivos digitais, em linha com Azevedo e Mariano (2009), para quem o mundo está cada vez mais informatizado com os recursos e potencialidades oferecidos pelas TIC, colaborando para a consolidação do GE como forma de controle estratégico dos tributos, como preconizado por Okot-Uma (2001) e Chen et al. (2006).

Em conjunto, tais resultados indicam que os dirigentes de empresas e contadores foram contrários às assertivas contidas nas questões 2 e 8 , revelando também que os auditores-fiscais não tiveram percepções contrárias às afirmações da pesquisa, sendo, todavia, observadas situações inconclusivas sobre as questões $2,3,5,6,7$ e 8 , nas quais se verificou apenas uma leve tendência à concordância, sendo constatado um valor pouco acima da média 3 , com moda e mediana também de 3 , mas, devido à alta variabilidade amostral em tais assertivas, há percepções contrárias sobre esses quesitos por parte de alguns respondentes. Por outro lado, os órgãos fiscalizadores perceberam de maneira mais expressiva apenas a afirmação 1 , os dirigentes de empresas foram bastante favoráveis às afirmações contidas nas questões 5,10 e 12 e concordaram ainda mais com as assertivas 1,4 e 9. Já os contadores tiveram concordância significativa com as afirmações $1,4,5,9$ e 10.

\subsection{Análise comparativa e discussão dos resultados quantitativos entre os grupos}

A Tabela 3 mostra as situações nas quais existiram as maiores diferenças de percepção entre os grupos de respondentes e como elas se deram. Destaca-se que não existiu nenhuma situação na qual fosse detectada diferença significativa entre os três grupos ao mesmo tempo: empresas, contadores e órgãos fiscalizadores. O que foi detectado, em algumas situações, foi a existência de dois grupos com percepções similares, em oposição a um terceiro. Isso foi verificado nas questões $2,4,5,6$ e 8 em que se percebeu similaridade entre empresas e contadores em oposição aos órgãos fiscalizadores. Já nas questões 9 e 12 houve uma similaridade entre órgãos fiscalizadores e contadores em oposição à percepção das empresas.

Como foi possível observar da análise da Tabela 3 há momentos em que a homogeneidade está entre os grupos de contadores e empresas. Noutros, porém, entre órgãos fiscalizadores e contadores. A avaliação comparativa dos respondentes revela que para os órgãos fiscalizadores há uma indiferença com tendência a perceber que as empresas já se encontravam preparadas para o SPED (média 3,213) e que houve redução, nas empresas, de custos operacionais em função da adoção desse sistema (média 3,138), o que foi negado pelo grupo formado por contadores e empresas (médias do grupo 2,265 e 2,205, respectivamente). Esse resultado corrobora os achados de Gegers (2012) que revelou que no Brasil, em 2012, 
90\% das empresas ainda não estavam preparadas para lidar com esse sistema nem com o correto cumprimento das obrigações acessórias por meio digital. Isso acontecia porque as empresas ainda precisam fazer diversos ajustes internos como a capacitação de mão de obra e investimentos em TIC. Em relação à divergência de percepção com relação à redução de custos, pode até ser que estes últimos acreditem no aumento, como preconizado por Meni (2012), que ponderava que o SPED eleva os gastos com treinamento de pessoal e preparação de equipes internas e clientes.

Tabela 3 - Comparação entre as percepções dos respondentes

\begin{tabular}{|c|c|c|c|c|c|c|c|c|c|c|c|c|}
\hline \multirow{2}{*}{$\begin{array}{c}\text { Questão } \\
\mathrm{N}^{\mathrm{o}} \\
\end{array}$} & \multicolumn{4}{|c|}{ Total da Amostra } & \multicolumn{4}{|c|}{ Órgãos Fiscalizadores } & \multicolumn{4}{|c|}{ Contadores e Empresas } \\
\hline & Média & $\begin{array}{l}\text { Desvio } \\
\text { Padrão }\end{array}$ & $\mathrm{N}$ & $\%$ & Média & $\begin{array}{l}\text { Desvio } \\
\text { Padrão }\end{array}$ & $\mathrm{N}$ & $\%$ & Média & $\begin{array}{l}\text { Desvio } \\
\text { Padrão }\end{array}$ & $\mathrm{N}$ & $\%$ \\
\hline 2 & 2,608 & 0,911 & 130 & 100 & 3,213 & 0,883 & 47 & 36 & 2,265 & 0,734 & 83 & 64 \\
\hline 4 & 4260 & 0 & 130 & 100 & 4 & 0,752 & 47 & 36 & 4,422 & 0,701 & 83 & 64 \\
\hline 5 & 3,823 & 0 & 130 & 100 & 3,298 & 0,907 & 47 & 36 & 4,12 & 0,802 & 83 & 64 \\
\hline 6 & 3,469 & 0,925 & 130 & 100 & 3,191 & 0,798 & 47 & 36 & 3,627 & 0,959 & 83 & 64 \\
\hline 8 & 2,538 & 1,065 & 130 & 100 & 3,138 & 0,824 & 47 & 36 & 2,205 & 1,045 & 83 & 64 \\
\hline Questão & \multicolumn{4}{|c|}{ Total da Amostra } & \multicolumn{4}{|c|}{ Órgãos Fiscalizadores e Contadores } & \multicolumn{4}{|c|}{ Empresas } \\
\hline $\mathrm{N}^{\circ}$ & Média & $\begin{array}{l}\text { Desvio } \\
\text { Padrão }\end{array}$ & $\mathrm{N}$ & $\%$ & Média & $\begin{array}{l}\text { Desvio } \\
\text { Padrão }\end{array}$ & $\mathrm{N}$ & $\%$ & Média & $\begin{array}{l}\text { Desvio } \\
\text { Padrão }\end{array}$ & $\mathrm{N}$ & $\%$ \\
\hline 9 & 4,023 & 0,976 & 130 & 100 & 3,816 & 1,009 & 98 & 75 & 4,656 & 0,483 & 32 & 25 \\
\hline 12 & 3,885 & 0,903 & 130 & 100 & 3,755 & 0,92 & 98 & 75 & 4,281 & 0,729 & 32 & 25 \\
\hline
\end{tabular}

Fonte: Dados da pesquisa.

A questão 4 confirma que houve aumento do compartilhamento de informações entre os órgãos fiscalizadores e as empresas na visão dos três grupos, havendo mais concordância no grupo formado por contadores e empresas (média 4,422) do que entre os órgãos fiscalizadores (média 4), confirmando Salvino et al. (2011), que ponderam que, diante dos avanços tecnológicos, da globalização e da necessidade de implementar novos processos, as empresas e o Fisco sentem que devem acompanhar esse novo cenário a fim de aumentar a integração e o compartilhamento de informações.

As questões 5 e 6 demonstram que o SPED contribuiu para a redução da sonegação e o aumento de arrecadação de tributos na visão do grupo formado por contadores e empresas (médias 4,120 e 3,627, respectivamente) havendo indiferença com tendência a concordância pelos órgãos fiscalizadores (médias 3,298 e 3,191, respectivamente), reforçando os argumentos de Sampaio (2007) que afirma que o SPED é uma ferramenta eficaz no combate à sonegação fiscal, e de Ilarino (2010), que relata que a informatização do sistema tributário, criada pelo Governo Federal, teve o objetivo de unificar e cruzar as informações contábeis e fiscais das empresas para aumentar a arrecadação de impostos.

Finalmente, a análise das questões 9 e 10 revela que a adoção do SPED provocou a necessidade de investimentos adicionais pelas entidades e que ele provocou mudanças culturais nelas na visão dos três grupos de respondentes, sendo que, no grupo formado por contadores e órgãos fiscalizadores (médias de 3,816 e 3,755, respectivamente), houve uma 
percepção menos significativa do que nas empresas, onde se percebeu um alto nível de concordância com os quesitos (médias de 4,656 e 4,281, respectivamente). Essas questões são explicadas por Gegers (2012), que revelou que empresas necessitaram de investimentos adicionais para lidarem com o SPED, e por Azevedo e Mariano (2009), ao relatarem que o SPED tem alterado a forma de cumprimento das obrigações, resultando na alteração da "cultura do papel", presente na sociedade, para a utilização de arquivos digitais.

\section{Apresentação e Análise dos Resultados da Pesquisa Qualitativa}

Após analisar os resultados sobre os impactos provocados pelo SPED e com o objetivo de avaliar as expectativas futuras de empresários, contadores e órgãos fiscalizadores sobre essa temática, desenvolveu-se uma pesquisa qualitativa por meio de quatro questões abertas. Assim, buscou-se relatar as percepções adicionais coletadas com os participantes do estudo. Salienta-se que tal parte da pesquisa permitiu não apenas examinar as diferentes percepções dos respondentes em relação ao tema proposto, mas também explorar como os fatos são articulados, confrontados e alterados e, ainda, fazer uma análise mais profunda sobre o problema investigado.

É importante destacar que, embora todos os respondentes estivessem centrados no mesmo tema e respondessem às mesmas perguntas, cada um teve a liberdade de responder conforme the conviesse, focalizando suas perspectivas particulares acerca da temática, trazendo, com isso, enriquecimento para o estudo.

Na visão das empresas, a utilização do SPED acarretará diversos reflexos positivos, tais como melhorias em qualificação profissional, tecnologia, desburocratização, qualidade da informação, gestão, controle e uso de recursos financeiros; redução de tempo, custos, fraudes, sonegação, erros e burocracia; uniformização e mais conscientização das obrigações fiscais, com diminuição das obrigações acessórias; inovação nas práticas contábeis; além de mais eficiência e eficácia na fiscalização, impactando tanto na agilidade e confiabilidade das informações, com modernização e otimização dos processos e em maior arrecadação de tributos, quanto na competitividade empresarial. Já os contadores apresentaram como principais pontos positivos o aumento na transparência, na qualidade e segurança das informações declaradas, na velocidade de acesso às informações, na arrecadação fiscal, na uniformização de informações fiscais, na agilidade dos contribuintes em cumprir as obrigações acessórias, na educação dos contribuintes e no reconhecimento profissional deles, além de exigência de maiores níveis de organização e controle e de mudanças socioculturais. Outros pontos ressaltados foram estes: a redução da informalidade, de custos administrativos, de retrabalho, de impactos no meio ambiente pelo menor uso de papel, da sonegação e da possibilidade de competição desleal, tendo em vista que a sonegação fiscal ficará mais difícil, como preconizado por Sampaio (2007), que visualiza o SPED como uma ferramenta eficaz no combate à sonegação. Uma das questões que os referidos profissionais ressaltaram para fazer frente à possibilidade de aumento na arrecadação tributária se refere à valorização do trabalho de planejamento tributário. Para os órgãos fiscalizadores a utilização do SPED acarretará diversos reflexos positivos, tais como rapidez na tramitação de documentos, redução na sonegação e aumento na arrecadação, maior controle de informações pelo Fisco, melhoria no cumprimento de obrigações acessórias das empresas e, especialmente, aumento no 
compartilhamento, na busca e na uniformização de informações, em linha com as premissas de Cleto (2008), que percebe o SPED como um projeto que visa melhorar o controle tributário, mediante o compartilhamento das informações contábeis e fiscais, de forma similar ao apontado pelos contadores.

Os pontos negativos ressaltados pelos dirigentes de empresas se referem à escassez de mão de obra, dificuldades de adequação ao SPED por parte das empresas, insegurança sobre quebra do sigilo fiscal e comercial das empresas; incremento nas exigências tecnológicas, assim como maior necessidade de investimentos em equipamentos e treinamento, além de aspectos relativos ao aumento nos riscos de transmissão de informações inadequadas, ao baixo tempo de adaptação e às altas multas em casos de não entrega das informações ou envios com erros. Em geral, os resultados sinalizaram que as empresas ainda não estão preparadas para utilizarem o SPED, sofrem com a falta de mão de obra qualificada e não desejam arcar com os custos relacionados a aumento de honorários ou salários de profissionais contábeis especializados, mas reconhecem que terão de fazê-lo. Os reflexos negativos do SPED apontados pelos contadores se referem à falta de preparo das empresas e dos governos para lidarem com esse sistema e às duplicidades de trabalho em alguns estados (que continuam obrigando o contribuinte a imprimir os livros), à maior dependência das empresas por tecnologia (especialmente softwares) e ao baixo comprometimento dos empresários brasileiros com o SPED. Eles destacaram a excessiva exposição das empresas, as dificuldades de algumas delas para se adaptaram às novas regras, o aumento de custos, tempo e talvez pessoal com o sistema, particularmente com treinamentos, compras e/ou desenvolvimento e implementação de sistemas. Os pontos negativos ressaltados pelos auditores fiscais foram mínimos e se referem às resistências a mudanças e ao aumento de custos como destacado pelos demais respondentes, também confirmados na pesquisa de Meni (2012).

Os empresários, quando questionados sobre os impactos do SPED nas relações entre empresas, contadores e órgãos fiscalizadores, disseram que esse sistema tende a estreitar as relações entre esses atores, deixando-as mais claras. Os empresários percebem que as empresas terão de se organizar para reduzir seu ônus tributário e obter lucro sem sonegarem, ou seja, por meio do planejamento tributário, ressaltando a importância dos contadores nesse processo e a aproximação com estes. Foi reafirmada a necessidade de um trabalho educativo ao invés de punitivo por parte dos órgãos fiscalizadores e a necessidade de consultorias e adequação dos processos gerenciais por parte das empresas. Essa questão alinhou-se ao pensamento dos auditores-fiscais. Os contadores entendem que esse sistema não só estreitará as relações, mas também estimulará mais organização, transparência e melhorias na comunicação, redução de erros, clareza e partilha de informações, redução de prazos, simplificação de processos, padronização de atividades e mais agilidade e controle. Alguns desses respondentes acreditam que haverá melhorias nos procedimentos e controles internos e externos, redução de processos burocráticos e de erros em processos, mais interação entre empresas e contadores, assim como mais intercâmbio de informações entre as empresas, contadores e governos. Os órgãos fiscalizadores também acreditam que esse sistema pode estreitar as relações, deixando-as mais claras e concordando, em parte, com as afirmações anteriores dos empresários e contadores, ressaltando os estímulos do SPED a mais organização, transparência e comunicação, clareza e partilha de informações, padronização de atividades e mais agilidade e controle, assim como à redução de erros, de burocracia, de

131 ISSN 2175-8069, UFSC, Florianópolis, v. 12, n. 26, p. 119-140, mai./ago. 2015 Revista Contemporậnea de Contabilidade 
prazos e a simplificação de processos. Na percepção desses respondentes, a sistemática de GE trazida pelo SPED reduz o desgaste na relação entre contadores e fiscais, provoca a diminuição do número de processos administrativos e torna o contribuinte mais responsável para cumprir as suas obrigações (principal e acessórias). Em geral, eles ressaltaram que o SPED elimina o preenchimento de vários livros e formulários referentes às obrigações contábeis fiscais, simplifica processos e efetua padronizações como redução de burocracia, de mão de obra e de controle e outras. Por consequência, facilita o inter-relacionamento entre os interessados.

Quando questionados sobre quais as principais repercussões que o SPED trará para empresas, dirigentes de empresas e órgãos fiscalizadores, as questões que emergiram da parte dos empresários foram o aumento de competitividade empresarial, a redução da sonegação e maior demanda de tecnologia e expertise para processamento, análise e gestão de informações, decorrentes da nova sistemática introduzida por esse sistema. Os respondentes indicaram igualmente que o SPED proporcionará economia de tempo e permitirá maior controle tributário sobre as organizações, reafirmando a necessidade de aceitação da nova cultura digital que se estabelece num ambiente em que o conhecimento é cada vez mais usado como o recurso estratégico responsável pelo sucesso e pelas vantagens competitivas de uma organização, corroborando os achados de Khalique e Isa (2014) e Durst e Ferenhof (2014). Dentre os comentários feitos pelos dirigentes de empresas, destaca-se a ideia de que o SPED "abriu o caminho" para se promover uma reforma tributária no Brasil, valorizando os bons profissionais que estejam dispostos a investir e, ao mesmo tempo, consigam manter-se técnica e academicamente atualizados para acompanharem os desafios propostos pela nova sistemática já instalada. Já os contadores enfatizaram uma mudança cultural e uma quebra de paradigmas, decorrentes da nova sistemática introduzida por esse sistema, ressaltando que o SPED aumentará a qualidade, confiabilidade e rapidez das informações, exigindo a implantação de controles internos mais rígidos, obrigando as empresas a descobrirem seus reais custos operacionais, a fazerem investimentos na profissionalização dos funcionários da área contábil, bem como eliminarem a "barreira" entre as empresas e Fisco, por meio da habitualidade/aproximação das relações entre essas partes. Já entre os órgãos fiscalizadores, uma das primeiras questões que emergiu foi o aumento de competitividade das empresas com a redução da sonegação e da demanda de tecnologia e expertise para processamento e análise de informações eletrônicas de dados decorrentes da nova sistemática introduzida por esse sistema de forma análoga ao observado entre os dirigentes de empresas. Além disso, os respondentes apontaram (i) a maior possibilidade de detecção de erros, redução nos custos e nas fraudes, maior produtividade, assim como (ii) melhorias nos recursos tecnológicos, econômicos e sociais.

Em conjunto, os resultados mostraram que os dirigentes de empresas, os contadores e órgãos fiscalizadores precisam se preparar melhor para o uso do SPED e suas inovações. Os dirigentes de empresas revelaram-se preocupados, mas bastante otimistas com o processo no futuro, revelando, todavia, que tiveram que arcar com os gastos e pagar mais uma vez pela ineficiência e despreparo do governo. Os contadores disseram que o sucesso do SPED dependerá, além de outros fatores, da visão que os contribuintes possuem desse sistema, pois está se revelando menos como uma ferramenta para melhorar os controles internos e aspectos tributários, e mais como uma obrigação acessória injusta e onerosa que, por vezes, gera problemas e inviabiliza o negócio de algumas empresas. Finalmente, dentre os comentários 
feitos pelos auditores fiscais, destaca-se a ideia de que o SPED ajudou a expandir as fronteiras da economia formal, ampliando os registros oficiais de entrada e saída de mercadoria, bem como os registros contábeis. Outros auditores ressaltaram a necessidade de realizar, além das fiscalizações de rotina, outros tipos de visitas às empresas com o fulcro de orientá-las e ajudálas a conhecerem e utilizarem melhor a sistemática vigente, concluindo que ainda é "preciso mais tempo de vida do sistema para analisar sua aplicabilidade e configurações para que esse possa ser um instrumento realmente eficiente". No geral, essa ideia foi amplamente acolhida, ganhando força e importância para o conjunto dos respondentes, que compreenderam que SPED é uma evolução necessária, e todos os atores envolvidos têm a ganhar, desde que o governo conduza bem a implementação dessa ferramenta, agindo como um parceiro das empresas e estimulando que os profissionais se adaptem à nova realidade. Outra ideia de impacto que foi um resultado surpreendente do estudo, pois não foi uma questão investigada diretamente, se relaciona à relevância dada pelos três grupos de respondentes para a gestão tributária, especialmente para os instrumentos de planejamento em tributos. Vários respondentes dos três grupos sinalizaram uma tendência de mais valorização de tal atividade, uma vez que o Estado quer reduzir ao máximo a sonegação e as empresas precisam pagar menos impostos (legalmente) para não serem consumidas pelo peso e complexidade do sistema tributário brasileiro, especialmente os empresários que acentuaram sua crescente preocupação com uma boa gestão tributária visando à redução lícita do ônus tributário (por meio da elisão fiscal).

\section{Considerações Finais}

O SPED é um tema de crescente importância que vem se destacando como uma das principais inovações organizacionais, tributárias e gerenciais, nos últimos tempos, no Brasil por promover mudanças tecnológicas em relação à escrituração contábil e fiscal de empresas, na sistemática de organização e controle das informações das empresas e na forma de fiscalização do governo. Apesar de o projeto ter sido implantado há vários anos, ainda existe uma ampla necessidade de conhecimento sobre esse tema, pois se sabe pouco sobre a visão dos diferentes atores envolvidos com esse sistema. Nesse sentido, a pesquisa descrita neste artigo teve como objetivo analisar a percepção de empresários, contadores e órgãos fiscalizadores de Minas Gerais sobre a adoção do SPED.

Os resultados, embora não possam ser indiscriminadamente generalizáveis, mostraram haver algumas percepções divergentes entre os empresários e contadores e os órgãos fiscalizadores e também há outras percepções convergentes. Esses resultados indicam que os auditores-fiscais perceberam que as empresas se encontram preparadas para o SPED, mas os empresários e os contadores revelaram que, de fato, isso foi uma avaliação errada de tal órgão governamental, pois, na verdade, elas ainda não se encontram preparadas. Os órgãos fiscalizadores acreditam na redução de custos com a implementação do SPED, mas os contadores e empresários indicam que isso não ocorreu; pelo contrário, apontaram aumentos de gastos com esse novo sistema. Uma das causas principais foi a necessidade de investimentos adicionais em equipamentos de informática, treinamento de pessoal $\mathrm{e}$ contratação de especialistas.

133 ISSN 2175-8069, UFSC, Florianópolis, v. 12, n. 26, p. 119-140, mai./ago. 2015 
Todas as três categorias de respondentes, contudo, perceberam, de maneira significativa, que, com a utilização do SPED, os órgãos fiscalizadores ficaram mais eficientes para identificar e combater fraudes tributárias; que esse sistema tem sido um meio seguro de transmissão das informações para os órgãos fiscalizadores, aumentou o compartilhamento de informações entre os órgãos fiscalizadores e as empresas; e que ele provocou mudanças culturais nas entidades contábeis, governamentais e principalmente nas empresariais. Os resultados revelaram com menos intensidade e uniformidade entre os respondentes, especialmente entre os órgãos fiscalizadores (que possuíam entendimentos divergentes entre si), que a adoção do SPED provocou investimentos adicionais nessas entidades e proporcionou melhorias no cumprimento das obrigações tributárias acessórias. Foi possível observar entre os empresários e contadores que o SPED contribuiu para redução da sonegação, para a valorização da profissão de contador e para um aumento na arrecadação de tributos e na fiscalização sobre as empresas, sendo que os órgãos fiscalizadores se manifestaram com certa indiferença, pois havia entendimentos divergentes entre as pessoas de tal grupo com leve tendência a concordância com essas assertivas. Embora os órgãos fiscalizadores tenham sido indiferentes sobre tais quesitos, os resultados indicam que alguns auditores-fiscais acreditam que isso será observado no futuro. Os dirigentes de empresas e contadores, em sua maioria, porém, entenderam que esses fatos já foram percebidos. Mesmo que auditores-fiscais acreditem, como pontos negativos do SPED, que haja resistências a mudanças e tendência de aumento de custos, eles entendem que parte das mudanças já se iniciou e tende a aumentar com o tempo na produtividade; melhorias nos recursos tecnológicos, econômicos e sociais; e demandas por serviços especializados, especialmente os baseados em TIC e serviços contábeis e/ou tributários, ressaltando o papel do governo em realizar ações educativas nas empresas, o que foi apontado como uma demanda dos empresários e contadores.

Os pontos negativos ressaltados pelos contadores e dirigentes de empresas se referem à escassez de mão de obra, falta de preparo dos profissionais e das entidades para lidar com o SPED, dificuldades de adequação ao sistema por parte das empresas, insegurança sobre quebra do sigilo comercial das empresas, exigências tecnológicas, assim como maior necessidade de investimentos em equipamentos e treinamento; além de aspectos relativos ao aumento nos custos operacionais e nos riscos de transmissão de informações inadequadas, ao baixo tempo de adaptação e às altas multas em casos de não entrega. Em geral, os resultados sinalizaram que as empresas ainda não estão preparadas para utilizarem o SPED e não desejam arcar com os custos relacionados a aumento de honorários ou salários de profissionais contábeis especializados, mas reconhecem que terão de fazê-lo.

O conjunto dos resultados mostrou um grau de concordância maior com as afirmativas propostas por parte dos empresários e o menor grau de concordância entre os órgãos fiscalizadores. No entanto, todos os três grupos de respondentes acreditam que a utilização do SPED acarretará em diversos reflexos positivos, trazendo um aumento de competitividade das empresas pela redução da sonegação e informalidade, provocada pela maior possibilidade de detecção de erros e fraudes. Além disso, o SPED colaborará para (i) redução de tempo, custos, fraudes, sonegação, erros e burocracia; (ii) uniformização e mais conscientização das obrigações fiscais, com diminuição das obrigações acessórias; (iii) inovação nas práticas contábeis e gerenciais; além de (iv) mais eficiência e eficácia na fiscalização, impactando na agilidade e confiabilidade das informações, com modernização e otimização dos processos e 
em maior arrecadação de tributos. Eles percebem que esse sistema poderá (v) estreitar as relações entre empresas, contadores e órgãos fiscalizadores, deixando-as mais claras e estimulando maior organização, responsabilidade, transparência e comunicação, padronização de atividades, agilidade e controle; além de (vi) promover uma minimização de erros, redução de prazos e simplificação de processos. Finalmente, foi percebido (vii) que os contadores e profissionais de tributos serão cada vez mais valorizados com o advento do SPED, especialmente os profissionais capacitados e atualizados cuja importância estratégica foi acentuada pelos dirigentes de empresas. Os empresários entenderam que (viii) as empresas terão de se organizar para reduzir seu ônus tributário e obter lucro sem sonegarem, ou seja, por meio do planejamento tributário, ressaltando a importância dos contadores nesse processo e a aproximação com estes. Foi reafirmada (ix) a necessidade de consultorias e adequação dos processos gerenciais por parte das empresas, e (x) o SPED tende a demandar mais tecnologia e expertise para processamento, análise e gestão de informações, proporcionando (xi) economia de tempo e permitindo maior controle tributário sobre as organizações, reafirmando a necessidade de aceitação da nova cultura, decorrentes da nova sistemática introduzida por esse sistema.

A despeito da relevância do tema e tendo em vista a limitação provocada pelo escopo regional da coleta de dados, fica a recomendação de que futuras pesquisas comparem diferenças de percepção entre interessados de outros estados ou regiões, ou realizem um estudo nacional ou supranacional.

As conclusões desta pesquisa ampliam o conhecimento do tema e ajudam a preencher uma lacuna de investigação, evidenciando que o SPED, mesmo com suas limitações, pode ser considerado um marco da chamada 'era digital', pois, de fato, modificou e aperfeiçoou a sistemática de controle tributário e transmissão de informações contábeis e fiscais das empresas para os órgãos fiscalizadores, aumentando a eficiência fiscal do governo e provocou significativos impactos contábeis, tributários e organizacionais, exigindo que as empresas e contadores inovassem em seus processos corporativos e de negócios. Adicionalmente, percebeu-se que os empresários, contadores e órgãos fiscalizadores precisam se preparar melhor para o uso do SPED, que é uma inovação organizacional e de negócios que veio para ficar, já tendo provocado, e ainda podendo provocar, significativas implicações gerenciais, técnicas, políticas e sociais. Em síntese, os respondentes indicam que o SPED representou um avanço tecnológico, modernizou o sistema de fiscalização tributária, provocou inovação nas práticas de escrituração contábeis e fiscais, está promovendo uma mudança cultural, exigiu o aprendizado de novas metodologias e técnicas, proporcionou transparência nas informações prestadas pelas empresas, fortaleceu o controle da fiscalização por meio de arquivos digitais, podendo reduzir a sonegação fiscal e aumentar a arrecadação do governo. As conclusões da pesquisa evidenciam também que o SPED (i) aperfeiçoou o cumprimento das obrigações tributárias acessórias; (ii) representa um avanço informacional e tecnológico; (iii) provocou inovação nos processos das empresas, dos escritórios contábeis e de órgãos fiscalizadores; (iv) aumentou o acesso do Estado às informações empresariais, proporcionando mais transparência e reduzindo a sonegação e evasão fiscal; e (v) exigiu o aprendizado de novas metodologias, processos e tecnologias. No geral, os resultados mostraram que os dirigentes de empresas, contadores e órgãos fiscalizadores precisam se preparar melhor para o uso do SPED e suas inovações, dedicando especial atenção às atividades de gestão tributária, apontada como central em um contexto de pressão por aumento de arrecadação, no qual as 
empresas precisam pagar menos impostos legalmente para não serem consumidas pelo peso e complexidade do sistema tributário brasileiro.

\section{Referências}

ABDENUR, R. Novas armas de combate à sonegação no país. 2001. Disponível em: $<$ http://www.etco.org.br/noticias/novas-armas-de-combate-a-sonegacao-no-pais/>. Acesso em: 8 ago. 2012.

AHMED, R. A.; RIDER, M. Pakistan's tax gap: estimates by tax calculation and methodology. Georgia State University. Andrew Young School of Policy Studies. International Studies Program Working Paper, p. 08-1, 2008.

ALLINGHAM, M. G.; SANDMO, A. Income tax evasion: a theoretical analysis. Journal of Public Economics, v. 1, n. 1, p. 323-338, 1972.

AMARAL, G. L. et al. Estudo sobre sonegação fiscal das empresas brasileiras. Instituto Brasileiro de Planejamento Tributário, 2009. Disponível em:

<http://www.ibpt.com.br/img/_publicacao/13649/175.pdf>. Acesso em: 8 ago. 2012

ANDRADE JR.; P. P; CERANTO, F. A. A. Um retrato bibliométrico da produção científica brasileira sobre Gestão da Tecnologia e da Inovação no período 2001-2011. Revista de Administração da UFSM, v. 6, n. 4, p. 708-719, 2013.

AZEVEDO, O. R.; MARIANO, P. A. SPED: sistema público de escrituração digital. São Paulo: IOB, 2009.

BARDIN, L. Análise de conteúdo. 3. ed. Lisboa: Edições 70, 2004

BEZERRA, R. L. Principais mudanças na contabilidade. 2011. Disponível em:

<http://www.clubedosContadores.com.br/>. Acesso em: 14 ago. 2012.

BRASIL. Código tributário nacional. Lei n. 5.172, de 25 de outubro de 1966. Dispõe sobre o Sistema Tributário Nacional e institui normas gerais de direito tributário aplicáveis à União, Estados e Municípios. Disponível em:

<http://www.planalto.gov.br/ccivil_03/leis/15172compilado.htm>. Acesso em: 9 ago. 2012.

BRASIL. Decreto ${ }^{\circ}$ 6.022, de 22 de janeiro de 2007. Institui o Sistema Público de Escrituração Digital - Sped. Disponível em http://www.receita.fazenda.gov.br/Legislacao/Decretos/2007/dec6022.htm. Acesso em 3 set. 2014.

BRASIL. Decreto $n^{\circ} 7.979$, de 8 de abril de 2013. Altera o Decreto $n^{\circ} 6.022$, de 22 de janeiro de 2007, que instituiu o Sistema Público de Escrituração Digital - Sped. Disponível em 
http://www.receita.fazenda.gov.br/Legislacao/Decretos/2013/dec7979.htm. Acesso em 3 set. 2014.

BRITTO, D. SPED: sistema público de escrituração digital. Revista Jus Vigilantibus, [online], 10 set. 2008. Disponível em <http://jusvi.com/artigos/35924>. Acesso em: 3 ago. 2012.

CHEN, Y. N. et al. E-government strategies in developed and developing countries: an implementation framework and case study. Journal of Global Information Management., [S.l.], v. 14, n. 1, p. 23-46, Jan./Mar. 2006.

CLETO, N. O que é SPED? Disponível em:

<http://www.ibef.com.br/ibefnews/pdfs/121/artigo.pdf>. Acesso em: 13 ago. 2012.

COMIN; E. R.; TEIXEIRA, R.; DURAYSKI, J.; SILVA, N. G.; VIEIRA, J. Investigando o fenômeno de compras coletivas on-line: fatores que influenciam a intensidade das compras. Revista de Administração da UFSM, v. 7, n. 2, p. 196-213, 2014.

COOPER, D. R.; SCHINDLER, P. S. Métodos de pesquisa em administração. 7. ed. Porto Alegre: Bookman, 2003.

DINIS, E. H. O governo eletrônico no Brasil: Perspectiva histórica a partir de um modelo estruturado de análise. Revista de Administração Pública. V. 43, Fev. 2009.

DUARTE, R. D. Big brother fiscal: o Brasil na era do conhecimento: como a certificação digital, SPED, e NF-e estão transformando a gestão empresarial no Brasil. 2 ed. São Paulo: Idea@work, 2008.

DUARTE, R. D. SPED e o sistema tributário brasileiro. 2009. Disponível em: $<$ http://www.robertodiasduarte.com.br/index.php/SPED-e-o-sistema-tributario-brasileiro/> Acesso em: 09 ago. 2012

EISENHARDT, K. Building theories from case study research. Academy of Management Review, v. 14, n. 14, p. 532-500, 1989.

ENGEL, E. M. R .A; HINES JR; J. R. Understanding tax evasion dynamics. NBER Working Paper Series. working paper N. 6903., 1999.

FUTEMA, M. S.; BASSO, L. F. C.; KAYO, E. K. Estrutura de capital, dividendos e juros sobre o capital próprio. Revista Contabilidade \& Finanças. São Paulo, v. 20, n. 49, p.44-62, jan/abr. 2009.

GEGERS, S. Maioria das empresas tem dificuldade em lidar com o SPED fiscal. [S.l.]: Infomoney, mar. 2012. Entrevista concedida a Karla Santana Mamona. Disponível em: 
$<$ http://www.ecofinancas.com/noticias/maioria-empresas-tem-dificuldade-lidar-SPED-fiscal>. Acesso em: 15 ago. 2012.

GEORGE, A.; BENNETT, G. Case studies and theory development in the social sciences. Cambridge: MIT Press, 2005.

GERON, C. M. S.; FINATELLI, J. R.; FARIA, A. C.; ROMEIRO, M. C. SPED - Sistema Público de Escrituração Digital: Percepção dos contribuintes em relação os impactos de sua adoção. REPeC - Revista de Educação e Pesquisa em Contabilidade, Brasília, v. 5, n. 2, art. 3, p. 44-67, maio/ago. 2011.

GRANLUND, M. Management accounting systems integration in corporate mergers: a case study. Accounting, Auditing and Accountability Journal, v. 16, n. 2, p. 208-243, 2003.

HAIR, J. F.; BLACK, W. C.; BABIN, B. J.; ANDERSON, R. E. Multivariate Data Analysis (7a. Ed). Prentice Hall: Upper Saddle River. 2010.

HAIR, J. F.; CELSI WOLFINBARGER, M. W.; MONEY, A. H.; SAMOUEL, P.; PAGE, M.. Essentials of Business Research Methods (2a. Ed). M. E. Sharpe: Armonk, New York. 2011.

ILARINO, S. SPED (sistema público de escrituração digital): impactos da sua implantação na empresa XX. E-civitas Revista Científica do Departamento de Ciências Jurídicas, Políticas e Gerenciais do Uni - BH, Belo Horizonte, v. 3, n. 1, jul. 2010.

INSTITUTO BRASILEIRO DE PLANEJAMENTO E TRIBUTAÇÃO. Brasileiro trabalhará até 31 de maio de 2014 para pagar tributos, aponta IBPT. 2014. Disponível em: https://www.ibpt.org.br/noticia/1691/Brasileiro-trabalhara-ate-31-de-maio-de-2014-parapagar-tributos-aponta-IBPT. Acesso em 3 set. 2014.

JICK, T. Mixing qualitative and quantitative methods: triangulation in action. Administrative Science Quarterly, v. 24, p. 602- 610, 1979.

JORDÃO, R. V. D.; NOVAS, J. C. A Study on the use of the balanced scorecard for strategy implementation in a large Brazilian mixed economy company. Journal of Technology Management \& Innovation, v. 8, p. 98-107, 2013.

JORDÃO, R. V. D.; SOUZA, A. A. Company's acquisition as a factor of change on the management control system: a strategic analysis from the perspective of the contingency theory. Revista Universo Contábil, v. 9, p. 75-103, 2013.

JORDÃO, R. V. D.; SOUZA, A. A.; AVELAR, E. A. Organizational culture and postacquisition changes in management control systems: An analysis of a successful Brazilian case. Journal of Business Research, v. 67, p. 542-549, 2014. 
JORDÃO, R. V. D.; PELEGRINI, F. G.; JORDÃO, A. C. T. Fatores críticos na gestão de projetos: um estudo de caso numa grande empresa latino-americana de classe mundial. Gestão \& Produção (UFSCAR. Impresso), v. 22, p. 280-294, 2015.

KASS, G. V. An Exploratory Technique for Investigating Large Quantities of Categorical Data, Applied Statistics, v. 29, n. 2, p. 119-127, 1980.

LIZOTE, S. A.; MARIOT, D. M. A estrutura do Sistema Público de Escrituração Digital (SPED): um estudo das novas obrigações. Navus - Revista de Gestão e Tecnologia.

Florianópolis, SC, v. 2, n. 2, p. 17 - 25, jul./dez. 2012

MAIA, R. Empresas precisam se adaptar à tributação digital. 2012. Disponível em: $<$ http://www.administradores.com.br/informe-se/administracao-e-negocios/empresasprecisam-se-adaptar-a-tributacao-digital/51515/>. Acesso em: 8 ago. 2012.

MENI, C. SPED: mais custo para empresas. 2012. Disponível em:

$<$ http://www.incorporativa.com.br/mostranews.php?ctg=8\&id=7633>. Acesso em: 15 ago. 2012.

OKOT-UMA, R. Electronic governance: re-inventing good governance. London: Commonwealth Secretariat London, 2001.

PINSKY, V. C.; DIAS, J. L.; KRUGLIANSKAS, I. Gestão estratégica da sustentabilidade e inovação. Revista de Administração da UFSM, v. 6, n. 3, p. 465-480, 2013.

RICHARDSON, G. Determinants of tax evasion: A cross-country investigation. Journal of International Accounting, Auditing and Taxation, v. 15, n. 1, p. 150-169, 2006.

SABAINI, J. C. G; JIMENEZ, J. P. Tax structure and tax evasion in Latin America. CEPAL, Economic Development Division. Santiago. 2012.

SALVINO, F. de S. et al. Os impactos que o SPED trouxe para a contabilidade. 2011. Monografia (Graduação em Ciências Contábeis) - Centro Universitário Ítalo Brasileiro, São Paulo, 2011. Disponível em: <http://pt.scribd.com/doc/83524260/10/Sub-Projetos-do-SPED>. Acesso em: 7 ago. 2012., 2011.

SAMPAIO, F. M. S. Módulo I - SPED - Sistema Público de Escrituração Digital. 2007. Disponível em: <http://pt.scribd.com/doc/77007483/SPED-Fiscal-Apostila>. Acesso em: 7 ago. 2012.

SIQUEIRA, M. L. A economia da sonegação: teorias e evidências empíricas. Revista de Economia Contemporânea. Rio de Janeiro, v. 9, n. 3, Set./Dez. 2005.

TANZI, V; SHOME, P. A Primer on Tax Evasion. Staff Papers - International Monetary Fund. v. 40, n. 4, p. 807-828. Publicado por Palgrave Macmillan Journals, 1993. 
TAX JUSTICE NETWORK. New report: developing countries want automatic information exchange. 2014. Disponível em: http://www.taxjustice.net/2014/06/24/new-reportdeveloping-countries-want-automatic-information-exchange. Acesso em: 3 set. 2014.

TAX JUSTICE NETWORK. The Cost of Tax Abuse, 2011. 2011. Disponível em: http://www.taxjustice.net/wp-content/uploads/2014/04/Cost-of-Tax-Abuse-TJN-2011.pdf. Acesso em: 3 set.2014.

TORGLER, B. The importance of faith: Tax morale and religiosity. Journal of Economic Behavior \& Organization. v. 61, n.1, p. 81-109, 2006. 